\title{
The current state of carinal resection and role of minimally invasive techniques
}

\author{
Andrei I. Gritsiuta ${ }^{1}$, Charles T. Bakhos ${ }^{2}$, Roman V. Petrov ${ }^{2}$ \\ ${ }^{1}$ Department of Surgical Services, University of Pittsburgh Medical Center, Pittsburgh, PA, USA; ${ }^{2}$ Department of Thoracic Medicine and Surgery, \\ Division of Thoracic Surgery, Lewis Katz School of Medicine at Temple University, Philadelphia, PA, USA \\ Correspondence to: Andrei I. Gritsiuta, MD, PhD. Department of Surgical Services, University of Pittsburgh Medical Center, 3600 Forbes Avenue, \\ Pittsburgh, PA 15213, USA. Email: gritsiutaai@upmc.edu. \\ Comment on: Chen J, Ang KL, Wang C, et al. Minimally invasive carinal reconstruction using bronchial flap and omental flap reinforcement. Ann \\ Thorac Surg 2021. [Epub ahead of print]. doi: 10.1016/j.athoracsur.2021.06.014.
}

Submitted Sep 11, 2021. Accepted for publication Sep 30, 2021.

doi: $10.21037 /$ tlcr-21-749

View this article at: https://dx.doi.org/10.21037/tlcr-21-749

\section{Background}

Lung cancer is a leading cause of cancer-related mortality in the United States with over 235,000 new cases in 2021 and nearly 132,000 deaths. Primary malignant tracheal neoplasms are rare tumors with an annual incidence of $0.1 / 100,000$ and account for $0.1 \%$ of all cancer deaths $(1,2)$. The most common histological types are squamous cell carcinoma (36-45\%) and adenoid cystic carcinoma (31-40\%) (3). Surgical resection is generally considered the best curative option for early-stage lung cancer as well as in a reasonable proportion of patients with clinical stage IIIb and stage IV disease (4). Adenoid cystic carcinoma has a tendency for submucosal spread and is associated with microscopically positive margins in $55 \%$ of patients (5). Therefore, R0 resection may be difficult to achieve without excessive anastomotic tension. In the surgical treatment of bronchogenic carcinoma, resection of the trachea-bronchial bifurcation is performed in less than $1 \%$ of patients with non-small cell lung cancer (NSCLC) and other low-grade neoplasms. Primary tracheal tumors are the main indication for a carinal resection with subsequent reconstruction (6).

Carinal resection is a technically challenging procedure. Although it has been performed for over 70 years, only recently have acceptable morbidity and mortality rates been achieved. The 5 -year survival rate after carinal resection for bronchogenic carcinoma varies from $21 \%$ to $44 \%$ and is highly dependent on the stage and the histology: $62 \%$ for adenoid cystic carcinoma and $46 \%$ for squamous cell carcinoma in N0 disease, $32 \%$ in N1, and $12 \%$ in N2/N3 disease (7-11).

Carinal resection for bronchogenic carcinoma is usually indicated for centrally located tumors within one centimeter of either main bronchi or invading the carina. Carinal resection can either be performed in isolation or be combined with parenchymal resection. The reported mortality for isolated carinal resection ranges from $3 \%$ to $12.7 \%$ in high volume centers compared to initial reports with $40 \%$ mortality rate $(8,10,12)$. Severe complications after carinal resections are mainly attributable to non-cardiogenic pulmonary edema with subsequent acute respiratory distress syndrome (ARDS) as well as anastomotic leak or stenosis, both of which remain a leading cause of postoperative mortality. The reported rate ranges between $2 \%$ and $8.5 \%$ (8). The incidence of anastomotic complications varies from $11 \%$ to $17 \%$ (11). The higher morbidity and mortality rates associated with carinal pneumonectomy, compared to isolated procedure, are due to the higher incidence (up to $14 \%$ of cases) of post pneumonectomy pulmonary edema and ARDS (11). Sleeve resection of the bronchus, the pulmonary artery or both provides complete tumor resection while avoiding pneumonectomy in centrally-located malignancies (13).

In light of the above, accurate staging is crucial in the preoperative setting. In addition, preoperative evaluation should include a full staging workup and careful physiologic assessment. Thorough bronchoscopy with multiple biopsies allow adequate assessment of the extent of neoplastic infiltration, which must be less than $2.0 \mathrm{~cm}$ of the distal 


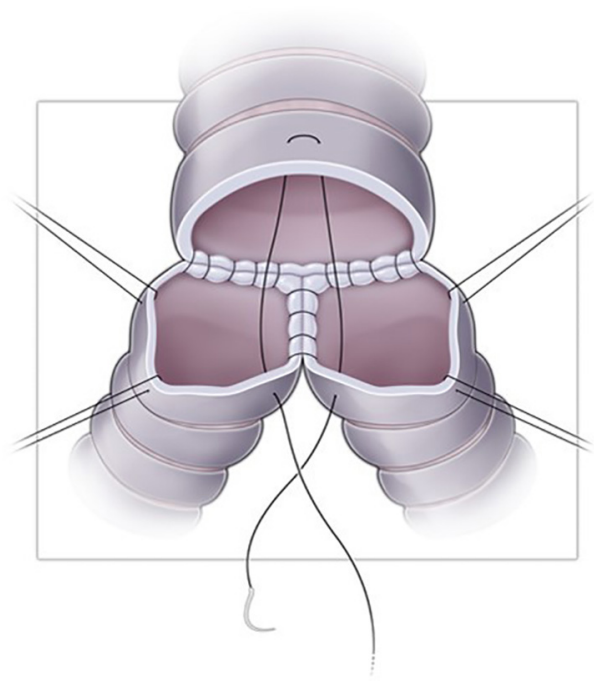

Figure 1 Tracheobronchial reconstruction with creation of a "neocarina" (bifurcating anastomosis of both main bronchi to the distal trachea).

segment of the trachea and $1.5 \mathrm{~cm}$ of the proximal end of the main bronchus to achieve tensionless anastomosis (8). Mediastinoscopy is indicated in all patients with central bronchogenic carcinoma to assess lymph node status. Same day mediastinoscopy with planned carinal resection is advisable to facilitate-dissection and may enhance proximal tracheal release. Otherwise, endobronchial ultrasound (EBUS) allows adequate sampling of the mediastinal lymph nodes for the purposes of the pathologic evaluation.

Tracheobronchial surgery has an extensive history predominated by several distinguished surgeons. Clement Price Thomas reported the first bronchial sleeve resection in 1947 and Philip Allison performed the first sleeve lobectomy for lung cancer in 1959 (14). In 1960, Paulson presented encouraging survival rates after bronchoplasty procedures for hilar carcinomas (15). The first successful central airway resection, reported by Belsey in 1946, involved lateral resection of the distal trachea and carina with subsequent reconstruction using stainless steel wire wrapped with free fascial graft (16). In 1950, Abbott performed the first successful right-sided sleeve pneumonectomy with lateral tracheal wall and partial left main bronchus resection (17). Isolated carinal resection without lung parenchyma was reported by Mathey in 1951 in France. In 1952 Kergin described bronchial flap for reconstruction of a large tracheal defect after pneumonectomy (18).

A classic primary carinal reconstruction with formation of a "neocarina" from both openings of the main bronchi (end-to-end right main bronchus to trachea anastomosis and end-to-side left main bronchus to bronchus intermedius) after resection of carinal adenoid cystic carcinoma was reported by Barclay in 1957 (19). This method of reconstruction is the most anatomic one, but with limited mobility of the newly created carina to the aortic arch (Figure 1). Multiple modifications of this approach have been reported without creation of a new tracheal bifurcation to reduce the tension of the suture line and make resection of long segments feasible (Figure 2): end-to-end anastomosis of the left main bronchus to the trachea with subsequent side-to-end anastomosis of the right main bronchus to the trachea or anastomosis itself (Miyamoto and Eschapasse modifications) (20). In 1982, Hermes Grillo reported his experience of 36 carinal resections with primary reconstruction, which was associated with a $13 \%$ operative mortality. He described an end-to-end anastomosis of the right main bronchus to the trachea with side-to-end anastomosis of the left main bronchus (21). However, the main disadvantage of end-to-side anastomoses is a lack of anatomic shape and two separate connections, which increases the risk of dehiscence.

According to Mulliken and Grillo, excessive tension of a newly formed anastomosis is the most common cause of postoperative morbidity and emphasize that the critical length of resection leading to anastomotic failure are those more than exceeding $4 \mathrm{~cm}$ (22). In 1982, Nohl-Oser proposed a tracheobronchoplastic procedure with bronchoplastic closure as an alternative to sleeve pneumonectomy in cases of massive noncircumferential airway defects and tumor-free contralateral wall of the main bronchus (23). The role of bronchospastic technique after extended noncircumferential resections for advanced bronchogenic carcinoma involving the carina or tracheobronchial angle was further expanded on by multiple authors (24-26). Bronchial flap reconstruction has been shown to be beneficial for excess anastomotic tension alleviation (27-29). The largest series of 73 patients who underwent bronchial flap reconstruction after carinal resections was reported by Peng et al. (27) in a retrospective study. Authors achieved reduction of anastomotic tension by "transformation of longitudinal tension of traditional end-to-end anastomosis into transverse tension that dispersed across a wide range of anastomosis" and a $\mathrm{V}$-shaped trim on the junction of trachea and bronchial flap. Additionally, tracheal microcirculation is preserved on a side of the bronchial wall with vascular pedicles. The major 


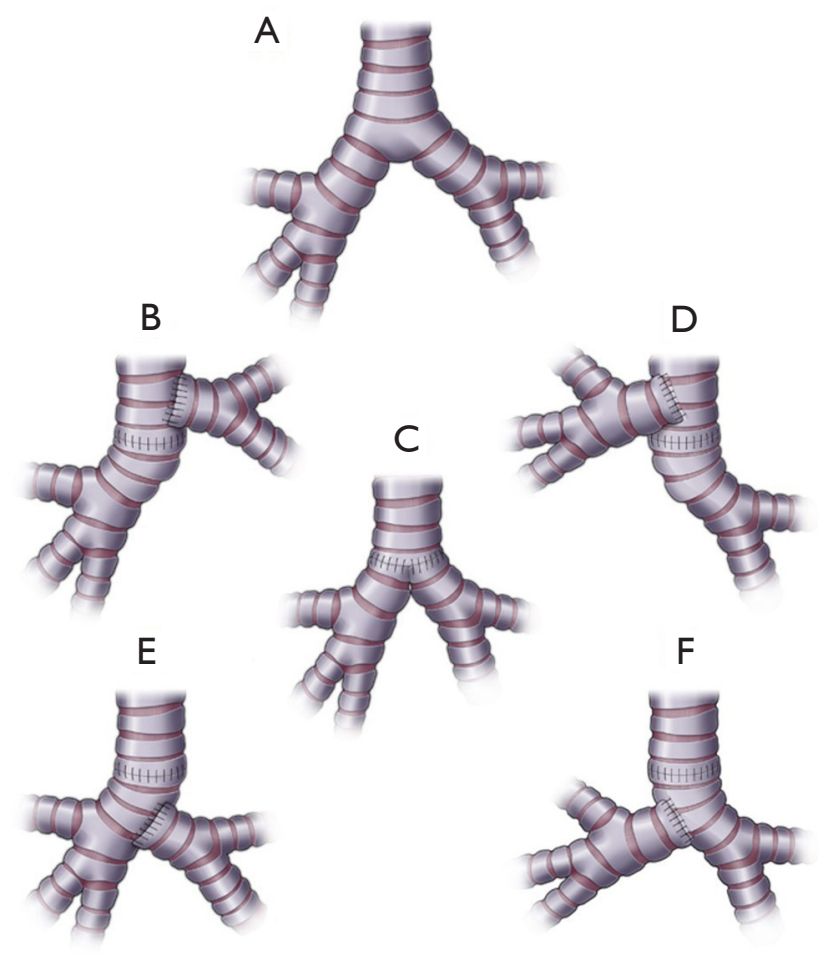

Figure 2 Types of the primary tracheobronchial reconstruction after carinal resection: (A) Normal anatomy; (B,E) End-to-end anastomosis of the trachea to the right main bronchus followed by end-to-side implantation of the left main bronchus to the (B) trachea or (E) right main bronchus; (C) Formation of a new carina: side-to-side anastomosis between the right and left main bronchi with subsequent end-to-end implantation to the trachea; $(\mathrm{D}, \mathrm{F})$ End-to-end anastomosis of the trachea to the left main bronchus followed by end-to-side implantation of the right main bronchus to the (D) trachea or (F) left main bronchus (from Petrov RV, Bakhos CT, Abbas AE. Carinal resection. Shanghai Chest 2018;2:84. doi: 10.21037/shc.2018.10.03; with permission).

contraindication to the described method was a defect of more than $50 \%$ of the airway circumference. Despite routine stump reinforcement with pedicled soft tissue flap, the rate of bronchopleural fistula and stenosis was 5.5\% and $2.7 \%$, respectively. Serious postoperative complications were reported in $17.8 \%$ of patient and the overall 30 -day mortality rate was $2.7 \%$. Authors concluded that there is no difference in postoperative complication rates, when comparing patients with airway resections of more or less than $4 \mathrm{~cm}$. (27).

In 1999, Kutlu and Goldstraw first described a continuous suture technique for the bronchial reconstruction after a sleeve lobectomy (30). According to recent literature, it has been shown that there is no significant difference in anastomotic related complications such as dehiscence, stenosis, or bronchopleural fistula between continuous and interrupted sutures $(10,31)$.

The bronchial anastomosis is usually covered with a soft tissue flap consisting of pleura, pericardial fat pad, pedicled muscle, or omentum flap to reduce the risk of anastomotic complications such as stenosis or dehiscence, particularly after neoadjuvant therapy or prior mediastinal irradiation. This flap also functions to separate the anastomosis from adjacent pulmonary vessels.

Classically, these techniques are executed via open approach through a right posterior lateral thoracotomy in the fourth or fifth intercostal space, a median sternotomy, or a "clamshell" incision to gain access to the carina and can be performed with sufficient length of the right main bronchus after resection.

\section{Minimally invasive carinal resection and reconstruction}

Video-assisted thoracoscopic surgery (VATS) has been proven to be superior to open surgery in terms of perioperative outcomes, such as length of hospital stay, pain control, perioperative complications and mortality, and quality of life in lung cancer patients. Following McKenna's first report of VATS sleeve lobectomy in 2006, VATS has been widely applied to both peripheral and central lung cancer resections in many centers and is considered the treatment of choice for early-stage NSCLC (32). Minimally invasive techniques have since further evolved to become less invasive, and now allow use of a uniportal technique (33-35). Few studies have been published that demonstrate less postoperative pain in the early postoperative period with the uniportal approach when compared to multiport techniques (33-35). The first uniportal VATS lobectomy was reported by Gonzalez et al. (36) in 2010, followed by report of a sleeve carinal resection in 2016 (35). Furthermore, robotic-assisted tracheobronchial interventions and carinal resections have been reported to be advantageous in anastomosis formation $(1,37,38)$.

VATS approach for carinal mucoepidermoid carcinoma was first described by Nakanishi et al. (39) in 2013. In 2014, Zhao et al. (40) reported the first successful minimally invasive tracheoplasty for squamous cell carcinoma of the mediastinal trachea, and a year later, Jiao et al. (41) performed the first sleeve tracheal resection for adenoid 
cystic carcinoma.

Refinements in anesthesia have allowed for effective airway management without compromising surgical expose. However, there is a slow adoption of VATS approach for carinal resection due to the technical complexity and narrow margin of error. Very few reports from highly specialized centers have been published to date. However, they clearly show the feasibility and safety of VATS in the treatment of malignant diseases of the carina and trachea (39,41-45). VATS approach aims to improve the outcomes of carinal resections, while maintaining the oncologic principles and capitalizing on the benefits of the minimally invasive surgery.

Airway management is especially paramount in minimally invasive tracheobronchial surgery. Bronchial blocker has been demonstrated to be an equal and potentially superior lung isolation technique for anatomic resections (46). Zhao et al. (40) described an endobronchial blocker for onelung ventilation during procedure and high-frequency jet ventilation (HFJV) during the anastomosis. Authors performed an end-to-end primary running anastomosis between the trachea and the left bronchus and then implanted end-to-side right main bronchus into the left main stem bronchus (LMSB). Despite common concern among surgeons that the use of HFJV could be a risk factor for development of ARDS, authors pointed out the HFJV, along with effective traction using endoscopic devices, makes VATS an effective and feasible approach for carinal resection with subsequent reconstruction. Cross-field ventilation through an additional port, however, remains a universally accepted strategy during VATS carinal resection. During partial reconstruction, a single-lumen tube can be utilized and advanced into the distal bronchus, avoiding the need for cross-field ventilation. Iriarte et al. (37) has described robotic LMSB resection through the right chest with distal LMSB cannulation via an armored endotracheal tube. Li et al. (43) and He et al. (44) summarized their experience of VATS resection and reconstruction of the carina or trachea, using cross-field ventilation, HFJV, and spontaneous breathing anesthesia with excellent results. Intubation of the opposite bronchus in the beginning of procedure and a jet ventilation catheter inserted through it during the reconstruction is another strategy predominantly used in uniportal VATS.

Jiang et al. (45) described another bold strategy of airway management during minimally invasive tracheobronchial surgery. Authors compared 18 patients who underwent VATS carinal resections under spontaneous ventilation to 14 patients in a control group using general endotracheal anesthesia. Shorter operative times, length of time for tracheal end-to-end anastomosis creation, and carinal reconstruction were reported in those undergoing spontaneous ventilation.

In the recent paper "Minimally invasive carinal reconstruction using bronchial flap and omental flap reinforcement", Chen and coauthors presented the feasibility of VATS approach and reviewed evaluation and management and surgical technique of such challenging scenario, as carinal adenoid cystic carcinoma (47). The presented case report of Chen $e t a l$. is an example of the increasing use of minimally invasive approach for complex carinal resection and reconstruction. The tumor involved the medial aspects of the bronchial wall of both main bronchi that allowed for noncircumferential resection and continuity preservation of the LMSB and reconstruction with a bronchial flap technique. The anastomosis was reinforced with an omental flap for prevention of anastomotic complications with an excellent outcome.

Carinal resection and reconstruction remains a challenging surgical problem that requires meticulous preoperative evaluations, technical finesse, and exceptional postoperative care for optimal surgical outcomes. Although traditionally performed through an open approach, minimally invasive techniques are becoming increasingly more common. Authors of the presented case report should be commended on their courageous approach to this challenging case with excellent surgical and oncologic outcomes.

\section{Acknowledgments}

We thank Dr. Leslie R. Elmore, DO (Department of Surgical Services, University of Pittsburgh Medical Center, Pittsburgh, PA) for careful reading and correction of the manuscript.

Funding: This research was funded in part through the NIH/NCI Cancer Center Support Grant P30 CA006927.

\section{Footnote}

Provenance and Peer Review: This article was commissioned by the editorial office, Translational Lung Cancer Research. The article did not undergo external peer review.

Conflicts of Interest: The authors have completed the ICMJE uniform disclosure form (available at https://dx.doi. org/10.21037/tlcr-21-749). The authors have no conflicts of 
interest to declare.

Ethical Statement: The authors are accountable for all aspects of the work in ensuring that questions related to the accuracy or integrity of any part of the work are appropriately investigated and resolved.

Open Access Statement: This is an Open Access article distributed in accordance with the Creative Commons Attribution-NonCommercial-NoDerivs 4.0 International License (CC BY-NC-ND 4.0), which permits the noncommercial replication and distribution of the article with the strict proviso that no changes or edits are made and the original work is properly cited (including links to both the formal publication through the relevant DOI and the license). See: https://creativecommons.org/licenses/by-nc-nd/4.0/.

\section{References}

1. Carvalho EA, Bonomi DO, Pinho AJM, et al. Carinal resection via robotic surgery: a safe approach for selected cases. J Bras Pneumol 2020;46:e20200118.

2. Petrov RV, Bakhos CT, Abbas AE. Carinal resection. Shanghai Chest 2018;2:84.

3. Honings J, Gaissert HA, van der Heijden HF, et al. Clinical aspects and treatment of primary tracheal malignancies. Acta Otolaryngol 2010;130:763-72.

4. Howington JA, Blum MG, Chang AC, et al. Treatment of stage I and II non-small cell lung cancer: Diagnosis and management of lung cancer, 3rd ed: American College of Chest Physicians evidence-based clinical practice guidelines. Chest 2013;143:e278S-313S.

5. Honings J, Gaissert HA, Weinberg AC, et al. Prognostic value of pathologic characteristics and resection margins in tracheal adenoid cystic carcinoma. Eur J Cardiothorac Surg 2010;37:1438-44.

6. Mathisen DJ, Grillo HC. Carinal resection for bronchogenic carcinoma. J Thorac Cardiovasc Surg 1991;102:16-22; discussion 22-3.

7. Costantino CL, Geller AD, Wright CD, et al. Carinal surgery: A single-institution experience spanning 2 decades. J Thorac Cardiovasc Surg 2019;157:2073-2083.e1.

8. Weder W, Inci I. Carinal resection and sleeve pneumonectomy. Thorac Surg Clin 2014;24:77-83.

9. de Perrot M, Fadel E, Mercier O, et al. Long-term results after carinal resection for carcinoma: does the benefit warrant the risk? J Thorac Cardiovasc Surg 2006;131:81-9.
10. Porhanov VA, Poliakov IS, Selvaschuk AP, et al. Indications and results of sleeve carinal resection. Eur J Cardiothorac Surg 2002;22:685-94.

11. Mitchell JD, Mathisen DJ, Wright CD, et al. Clinical experience with carinal resection. J Thorac Cardiovasc Surg 1999;117:39-52; discussion 52-3.

12. Tapias LF, Ott HC, Mathisen DJ. Complications Following Carinal Resections and Sleeve Resections. Thorac Surg Clin 2015;25:435-47.

13. Deslauriers J, Grégoire J, Jacques LF, et al. Sleeve lobectomy versus pneumonectomy for lung cancer: a comparative analysis of survival and sites or recurrences. Ann Thorac Surg 2004;77:1152-6; discussion 1156.

14. Thomas CP. Conservative resection of the bronchial tree. J R Coll Surg Edinb 1956;1:169-86.

15. Paulson DL, Shaw RR. Results of bronchoplastic procedures for bronchogenic carcinoma. Ann Surg 1960;151:729-40.

16. Belsey R. Stainless steel wire suture technique in thoracic surgery. Thorax 1946;1:39-47.

17. Abbott OA. Experiences with the surgical resection of the human carina, tracheal wall, and contralateral bronchial wall in cases of right total pneumonectomy. J Thorac Surg 1950;19:906-22.

18. Kergin FG. Carcinoma of the trachea. J Thorac Surg 1952;23:164-8.

19. Barclay RS, McSwan N, Welsh TM. Tracheal reconstruction without the use of grafts. Thorax 1957;12:177-80.

20. Yamamoto K, Miyamoto Y, Ohsumi A, et al. Surgical results of carinal reconstruction: an alterative technique for tumors involving the tracheal carina. Ann Thorac Surg 2007;84:216-20.

21. Grillo HC. Carinal reconstruction. Ann Thorac Surg 1982;34:356-73.

22. Mulliken JB, Grillo HC. The limits of tracheal resection with primary anastomosis: further anatomical studies in man. J Thorac Cardiovasc Surg 1968;55:418-21.

23. Nohl-Oser HC, Fenn A, Dottori V. Tracheobronchoplastic procedure in the treatment of advanced carcinoma of the right upper lung. Ann Thorac Surg 1982;33:396-9.

24. Tong WP. Autogenous bronchial pedicle flap for tracheoplastic procedures. Zhonghua Wai Ke Za Zhi 1992;30:623-4, 637

25. Ozcelik C, Onat S. Nohl-Oser type tracheobronchoplastic procedure in the treatment of advanced carcinoma of the right upper lobe. Interact Cardiovasc Thorac Surg 2004;3:277-9. 
26. Sato M, Hasegawa S, Shoji T, et al. Tracheobronchoplasty for resection of lung cancer arising from a tracheal bronchus. Ann Thorac Surg 2002;73:310-2.

27. Peng Q, Zhang L, Ren Y, et al. Reconstruction of Long Noncircumferential Tracheal or Carinal Resections With Bronchial Flaps. Ann Thorac Surg 2019;108:417-23.

28. He WX, Han BQ, Liu M, et al. Tracheobronchial reconstructions with bronchoplastic closure: an alternative method in treatment of bronchogenic carcinoma involving the carina or tracheobronchial angle. J Thorac Cardiovasc Surg 2012;144:418-24.

29. Ren YJ, Zheng H, Shen LX, et al. A Novel Technique of Long-Segment Tracheal Repair With Extended Bronchial Flap of Right Upper and Main Bronchus Plus Tracheoplasty. Ann Thorac Surg 2015;99:2188-90.

30. Kutlu CA, Goldstraw P. Tracheobronchial sleeve resection with the use of a continuous anastomosis: results of one hundred consecutive cases. J Thorac Cardiovasc Surg 1999;117:1112-7.

31. Palade E, Holdt H, Passlick B. Bronchus anastomosis after sleeve resection for lung cancer: does the suture technique have an impact on postoperative complication rate? Interact Cardiovasc Thorac Surg 2015;20:798-804.

32. McKenna RJ Jr, Houck W, Fuller CB. Video-assisted thoracic surgery lobectomy: experience with 1,100 cases. Ann Thorac Surg 2006;81:421-5; discussion 425-6.

33. Gonzalez-Rivas D, Soultanis KM, Garcia A, et al. Uniportal video-assisted thoracoscopic lung sparing tracheo-bronchial and carinal sleeve resections. J Thorac Dis 2020;12:6198-209.

34. Lyscov A, Obukhova T, Ryabova V, et al. Double-sleeve and carinal resections using the uniportal VATS technique: a single centre experience. J Thorac Dis 2016;8:S235-41.

35. Sekhniaidze D, Gonzalez-Rivas D. Uniportal videoassisted thoracoscopic sleeve resection. Ann Cardiothorac Surg 2016;5:145-6.

36. Gonzalez D, Paradela M, Garcia J, et al. Single-port videoassisted thoracoscopic lobectomy. Interact Cardiovasc Thorac Surg 2011;12:514-5.

37. Iriarte F, Abbas AE, Petrov R, et al. Right transthoracic approach for robotic left main stem bronchus sleeve resection. JTCVS Techniques 2021. In press. doi: 10.1016/ j.xjtc.2021.07.005.

38. Hu D, Wang Z, Tantai J, et al. Robotic-assisted thoracoscopic resection and reconstruction of the carina. Interact Cardiovasc Thorac Surg 2020;31:912-4.

39. Nakanishi R, Yamashita T, Muranaka K, et al. Thoracoscopic carinal resection and reconstruction in a patient with mucoepidermoid carcinoma. J Thorac Cardiovasc Surg 2013;145:1134-5.

40. Zhao G, Dong C, Yang M, et al. Totally thoracoscopic tracheoplasty for a squamous cell carcinoma of the mediastinal trachea. Ann Thorac Surg 2014;98:1109-11.

41. Jiao W, Zhu D, Cheng Z, et al. Thoracoscopic tracheal resection and reconstruction for adenoid cystic carcinoma. Ann Thorac Surg 2015;99:e15-7.

42. Xu X, Chen H, Yin W, et al. Thoracoscopic half carina resection and bronchial sleeve resection for central lung cancer. Surg Innov 2014;21:481-6.

43. Li J, Wang W, Jiang L, et al. Video-Assisted Thoracic Surgery Resection and Reconstruction of Carina and Trachea for Malignant or Benign Disease in 12 Patients: Three Centers' Experience in China. Ann Thorac Surg 2016;102:295-303.

44. He J, Wang W, Li J, et al. Video-assisted thoracoscopic surgery tracheal resection and carinal reconstruction for tracheal adenoid cystic carcinoma. J Thorac Dis 2016;8:198-203.

45. Jiang L, Liu J, Gonzalez-Rivas D, et al. Thoracoscopic surgery for tracheal and carinal resection and reconstruction under spontaneous ventilation. J Thorac Cardiovasc Surg 2018;155:2746-54.

46. Kosarek L, Busch E, Abbas A, et al. Effective use of bronchial blockers in lung isolation surgery: an analysis of 130 cases. Ochsner J 2013;13:389-93.

47. Chen J, Ang KL, Wang C, et al. Minimally invasive carinal reconstruction using bronchial flap and omental flap reinforcement. Ann Thorac Surg 2021. [Epub ahead of print]. doi: 10.1016/j.athoracsur.2021.06.014.
Cite this article as: Gritsiuta $\mathrm{AI}$, Bakhos CT, Petrov RV. The current state of carinal resection and role of minimally invasive techniques. Transl Lung Cancer Res 2021;10(10):4029-4034. doi: $10.21037 /$ tlcr-21-749 